NBER WORKING PAPER SERIES

BUBBLES IN PRICES OF EXHAUSTIBLE RESOURCES

\author{
Boyan Jovanovic \\ Working Paper 13320 \\ http://www.nber.org/papers/w13320 \\ NATIONAL BUREAU OF ECONOMIC RESEARCH \\ 1050 Massachusetts Avenue \\ Cambridge, MA 02138 \\ August 2007
}

I thank Peter Rousseau and Victor Tsyrennikov for discussion and for helping organize the data. Thanks also to David Ashmore at Liquid Assets, Simon Berry, Guillaume Daudin, Pete Duffy, Lynda McLeod at Christies Archives, Ana Maria Santacreu and Alan Taylor-Restell for help with the data, Orley Ashenfelter, Robert Bohr, Dennis Foley, Lu Han, Hiroyuki Kasahara, John Leahy, Steven LeRoy, Robert Lucas, Alejandro Rodriguez, Manuel Santos, Chris Shipley, Larry Stone, Ivan Werning and Michael Woodford for comments, and the NSF for support. The views expressed herein are those of the author(s) and do not necessarily reflect the views of the National Bureau of Economic Research.

(C) 2007 by Boyan Jovanovic. All rights reserved. Short sections of text, not to exceed two paragraphs, may be quoted without explicit permission provided that full credit, including $\odot$ notice, is given to the source. 
Bubbles in Prices of Exhaustible Resources

Boyan Jovanovic

NBER Working Paper No. 13320

August 2007

JEL No. E44,G12

\section{ABSTRACT}

Aside from the equilibrium that Hotelling (1931) displayed, his model of non-renewable resources also contains a continuum of bubble equilibria. In all the equilibria the price of the resource rises at the rate of interest. In a bubble equilibrium, however, the consumption of the resource peters out, and a positive fraction of the original stock continues to trade forever. And that may well be happening in the market for high-end Bordeaux wines.

Boyan Jovanovic

New York University

Department of Economics

19 W. 4th Street, 6th Floor

New York, NY 10012

and NBER

Boyan.Jovanovic@nyu.edu 


\title{
Bubbles in Prices of Exhaustible Resources*
}

\author{
Boyan Jovanovic ${ }^{\dagger}$
}

July 26, 2007

\begin{abstract}
Aside from the equilibrium that Hotelling (1931) displayed, his model of non-renewable resources also contains a continuum of bubble equilibria. In all the equilibria the price of the resource rises at the rate of interest. In a bubble equilibrium, however, the consumption of the resource peters out, and a positive fraction of the original stock continues to be traded forever. And that may well be happening in the market for high-end Bordeaux wines.
\end{abstract}

\section{Introduction}

If an economy can sustain a rational bubble at all, then any durable good that is in fixed supply is a potential candidate for a bubble. Non-renewable resources are such durables; an inflating bubble on such goods cannot defeat itself by eliciting supply that exceeds what asset holders are willing to hold.

The simplest model of non-renewable resources is that of Hotelling (1931). Aside from the equilibrium that he defines, his model also contains a continuum of bubble equilibria. This follows because in Hotelling's world the price of the resource must rise at the rate of interest even without the bubble, and so one can easily designate a fraction of the resource as destined for eternal storage - all this does is to raise the initial price of the resource. And that, more or less, is what Dasgupta and Heal (1979, Ch. 8) show in a GE setting but with exogenous saving so that issues like transversality conditions did not come up. Tirole (1985, sec. $7[\mathrm{~b}])$ connects their argument to the existence of bubbles, but only informally and a bit differently from

${ }^{*}$ I thank Peter Rousseau and Victor Tsyrennikov for discussion and for helping organize the data. Thanks also to David Ashmore at Liquid Assets, Simon Berry, Guillaume Daudin, Pete Duffy, Lynda McLeod at Christies Archives, Ana Maria Santacreu and Alan Taylor-Restell for help with the data, Orley Ashenfelter, Robert Bohr, Dennis Foley, Lu Han, Hiroyuki Kasahara, John Leahy, Steven LeRoy, Robert Lucas, Alejandro Rodriguez, Manuel Santos, Chris Shipley, Larry Stone, Ivan Werning and Michael Woodford for comments, and the NSF for support.

${ }^{\dagger}$ New York University. 


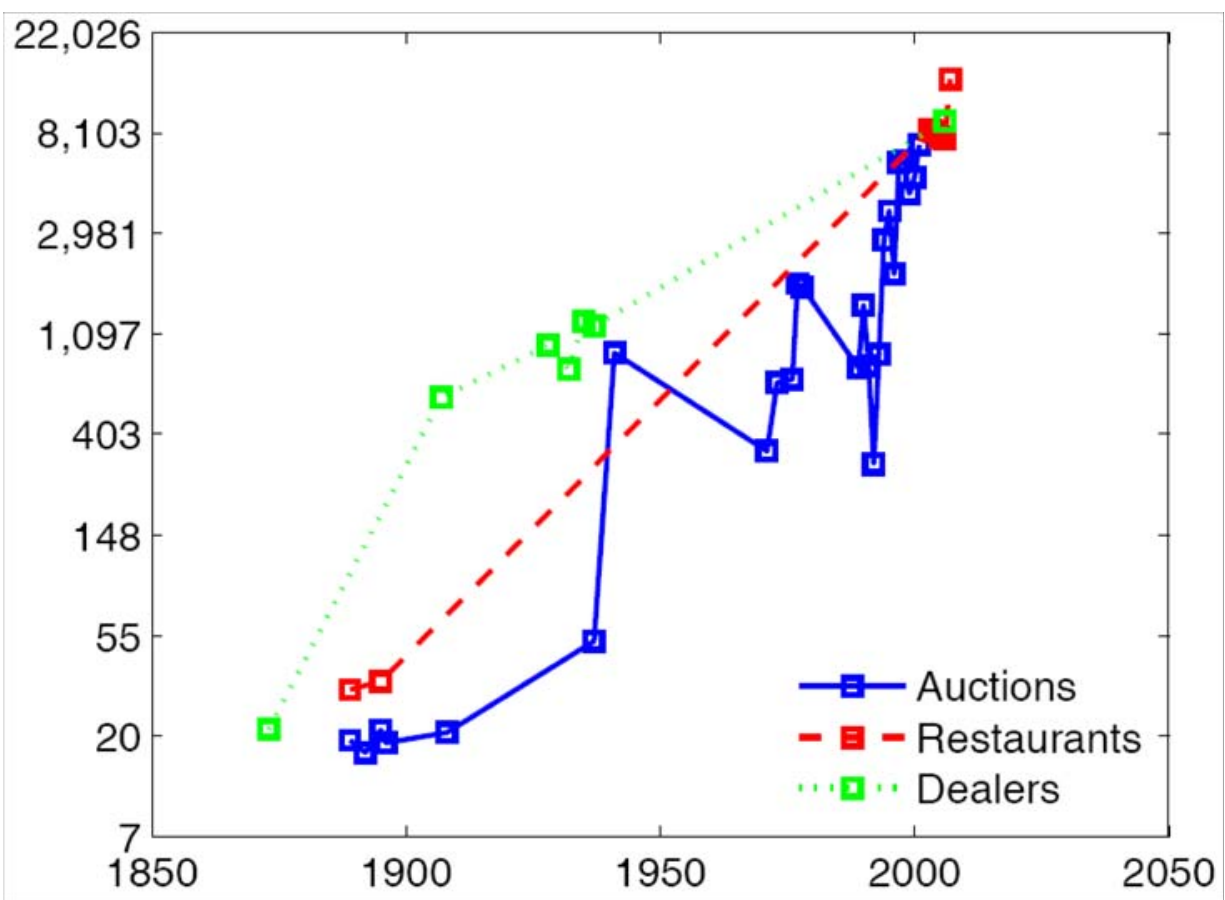

Figure 1: The time Series: The Price of A Bottle of the 1870 LAfite, in YEAR-2000 DOLLARS

how we shall see it done here. The results are starker in Hotelling's (1931) partial equilibrium context, moreover, and they add value in ways we shall note as we go along.

I then look at the market for vintage wines using original data, and they suggest that bubbles exist on some top vintages such as the old red Bordeaux wines. ${ }^{1}$ The reason for thinking that an 1870 Lafite, e.g., serves primarily as an investment, is that there is very little evidence of its stock being consumed as time passes, but plenty of evidence of continued active trading in the asset at auctions run by Christie's, Sotheby's, etc..

Figure 1 shows the history of prices for a bottle of the 1870 Lafite, prices at auction, prices in restaurants, and prices offered by dealers. The data for this wine are incomplete as they are for all the wines in my sample, but the Figure describes fairly well what the entire sample shows: Consumption occurs early, and later transactions mainly reallocate assets. Consumption demand is typically met by dealers and restaurants, and not by purchases at auction where the buyers are restaurants, dealers and private collectors. The wine's average rate of price increase is 5.29 percent (auctions), 5.15 percent (restaurants) and 4.54 percent (dealers). The point of the

\footnotetext{
${ }^{1}$ Good surveys of the market for wine and for fine art are Ashenfelter and Graddy (2003) and Burton and Jacobsen (1999).
} 


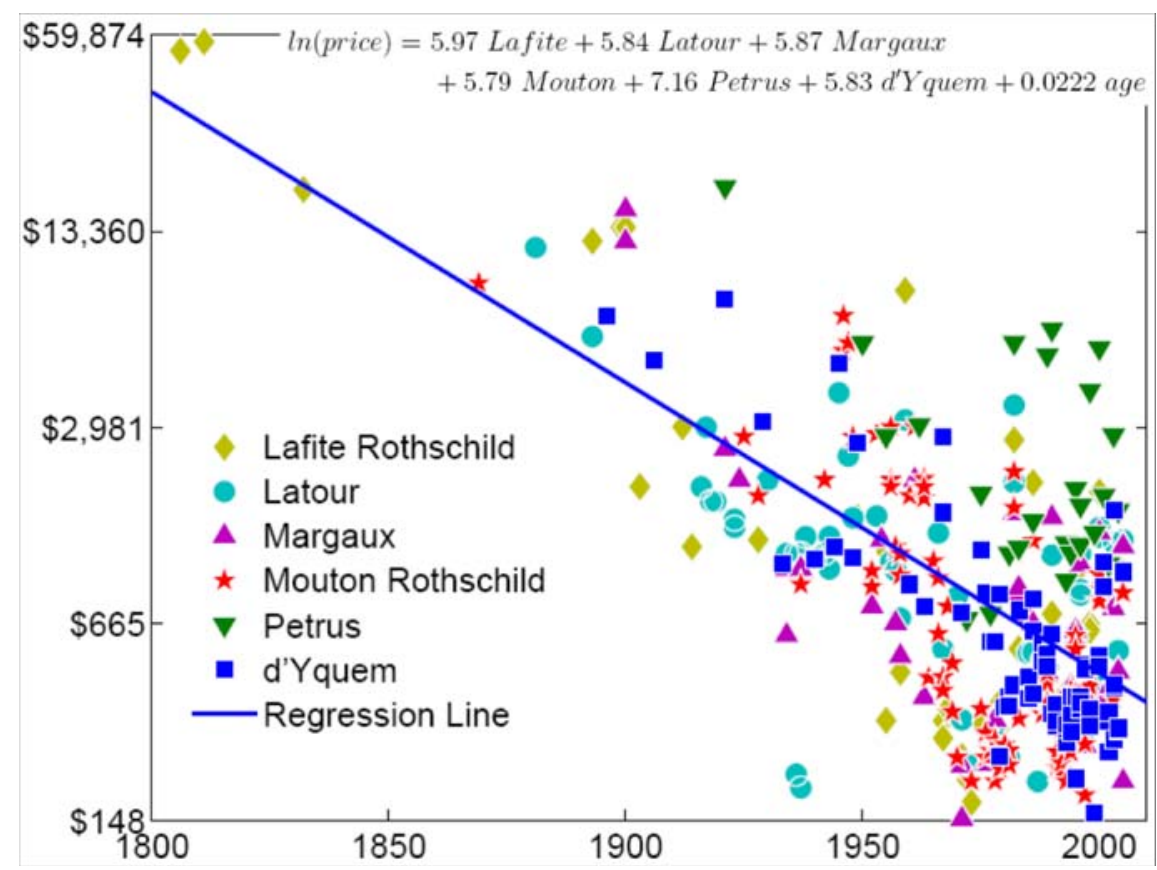

Figure 2: The Cross SeCtion: April 2007 DeAler Prices Per Bottle for VARIOUS VINTAGES

graph is that the red and green squares predominate in the early years of the wine's life, whereas the blue dots are spread out more evenly and predominate in the more recent period. Dealers offered the 1870 Lafite for sale in the first few decades of its life, and more recently it has shown up at many auctions. Moreover, the blue dots represent actual transactions, whereas the red and green dots indicate that the wine was offered for sale on a wine list, but not necessarily sold. ${ }^{2}$ This pattern is typical of the wines in the sample, and similar graphs are reported in the Appendix.

The cross section evidence is just as dramatic. Figure 2 shows prices per bottle at which the Antique Wine Co., a wine dealer, offered various vintages of six Bordeaux wines. The low (2.2 percent per year ) cross-section return to age reflects the fact that young wines have recently been appreciating faster than old wines, arguably because of the higher convenience yield that the storage of older wines entails, especially to a restaurant when it displays the old vintage on its wine list. A bottle of the 1811 Lafite costs $\$ 60,000 .^{3}$

\footnotetext{
${ }^{2}$ In particular, the cluster of red dots in the years 2003-7 represents the sale price at the same (Chicago's Charlie Trotter's) restaurant where the bottle has been offered for sale (but presumably has not sold). See the Appendix table for an account of all the data plotted in Figure 1.

${ }^{3}$ Not in the data is the 1787 Lafite for which the record price was set at 1985 at a Christies auction by Malcolm Forbes, the late publisher, when he paid US $\$ 156,450$ for it. Analysis then showed that the bottle was at least half full of the 1962 vintage of the same wine.
} 
Plan of paper.- Section 2 presents the partial equilibrium, one-capital "Hotelling" version which also contains the main argument. The strategy is to present the simplest case first, and then do several robustness checks. Section 3 tests for the presence of bubbles using data on vintage wines. Section 4 describes a general-equilibrium version of the one-capital case showing when a rational bubble is feasible. The Appendix describes the data, extends the Hotelling model to the multi-capital case, and poses the Planner's problem when there is a convenience yield to the storage of capital.

\section{Partial equilibrium}

Consider a non-renewable resource, or "capital," that does not depreciate, and that cannot be augmented via investment or discovery. The price of consuming it must rise at the rate of interest in order for suppliers to be indifferent between selling it now or later. But when price rises at the rate of interest, agents are also happy to hold the resource for the purpose of simply re-selling it. If one could invest in new capital, such investment would become increasingly profitable over time, and additional supply would keep prices down. But since such additions are impossible, a rational bubble can form.

Hotelling's (1931) version of the problem goes as follows. Let the interest rate be $r$, and let the market demand for consuming the capital be $x=D(p)$. Capital can be delivered to consumers costlessly. ${ }^{4}$ Suppose that $D(p)>0$ for all $p<\infty$, implying an unbounded willingness to pay at small levels of consumption, which translates into an Inada condition on the utility function. ${ }^{5}$ The capital must then be consumed at every date for, if at some date it were not consumed, its price would at such dates be infinite. But if supply is to be positive at each date, we must have

$$
p_{t}=p_{0} e^{r t}
$$

for some $p_{0}>0 .^{6}$

Hotelling's equilibrium. - To solve for $p_{0}$, Hotelling requires that the resource be fully exhausted:

$$
k_{0}=\int_{0}^{\infty} D\left(p_{0} e^{r t}\right) d t .
$$

Since $D$ is strictly monotone, the solution for $p_{0}$ is unique and so, therefore, is equilibrium, and also the social optimum. ${ }^{7}$ Moreover, at each date the price, $p_{t}$, of the asset equals the present value of the stream of dividends to which it is a claim.

\footnotetext{
${ }^{4}$ The introduction of extraction costs would not change the results.

${ }^{5}$ We relax this in subsection 2.1.5

${ }^{6}$ We interpret $r$ as net of any convenience yield or carrying costs of holding the asset. Wine storage is, in any case cheap, as low as $\$ 1.32$ per case per month, i.e., $\$ 1.32$ per standard bottle per year. We analyze storage costs (the opposite of convenience yield) in Section 2.1.3.

${ }^{7}$ The GE version of the Planner's problem is analyzed in Section 4.
} 


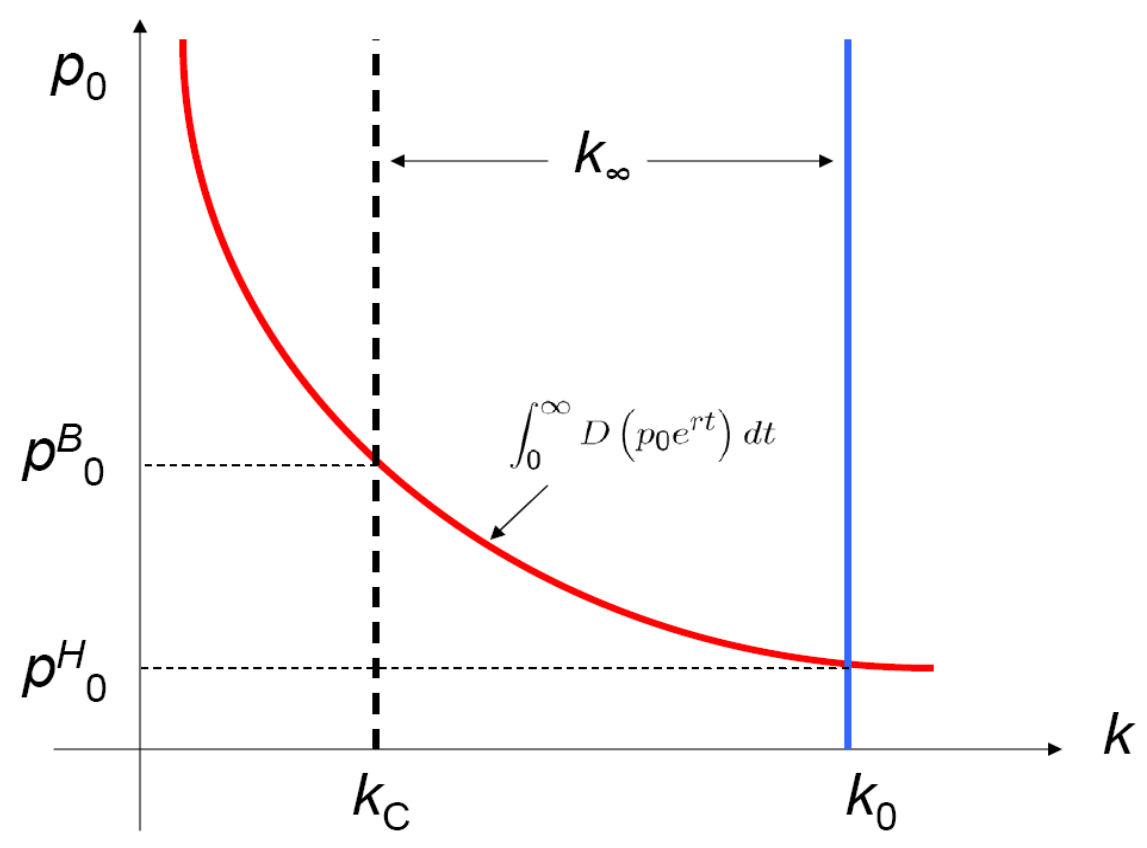

Figure 3: The Determination of The EQUilibria

Pure strategy bubble equilibria. - In the Hotelling equilibrium all sales are to consumers, with each produce. Each producer chooses a date at which to sell. A continuum of other equilibria may exist, however: A fraction of $k_{0}$ may never be sold. We replace (1) by two conditions. The first states that $k_{0}$ is divided into a stock, $k_{c}$, that will at some point be consumed, and a stock, $k_{\infty}$, that speculators hold for ever:

$$
k_{0}=k_{c}+k_{\infty} .
$$

The second states that $k_{c}$ is eventually exhausted:

$$
k_{c}=\int_{0}^{\infty} D\left(p_{0} e^{r t}\right) d t .
$$

Hotelling's equilibrium is the one for which $k_{c}=k_{0}$. The rest are pure-strategy bubble equilibria. In such an equilibrium, each agent decides whether to hold the wine for ever as an asset or whether to sell to consumers at a particular date. Figure 3 shows how the initial prices $p_{0}$ are determined - the Hotelling equilibrium, $p_{0}^{\mathrm{H}}$ is the lowest, and in a bubble equilibrium the date-zero prices, $p_{0}^{B}$, are higher. Any $k_{\infty} \in\left[0, k_{0}\right)$ is valid as long as the economy can absorb the bubble - see (33) for a sufficient condition. Future sellers and speculators earn the same present value of revenues at each date, and there is no gains to arbitrage between the two markets. Figure 4 plots $k_{t}$ in the left panel and the relation between consumption and trading of $k$ in the right panel, where it is assumed that a constant fraction, $v$, of $k_{t}$ trades in each 

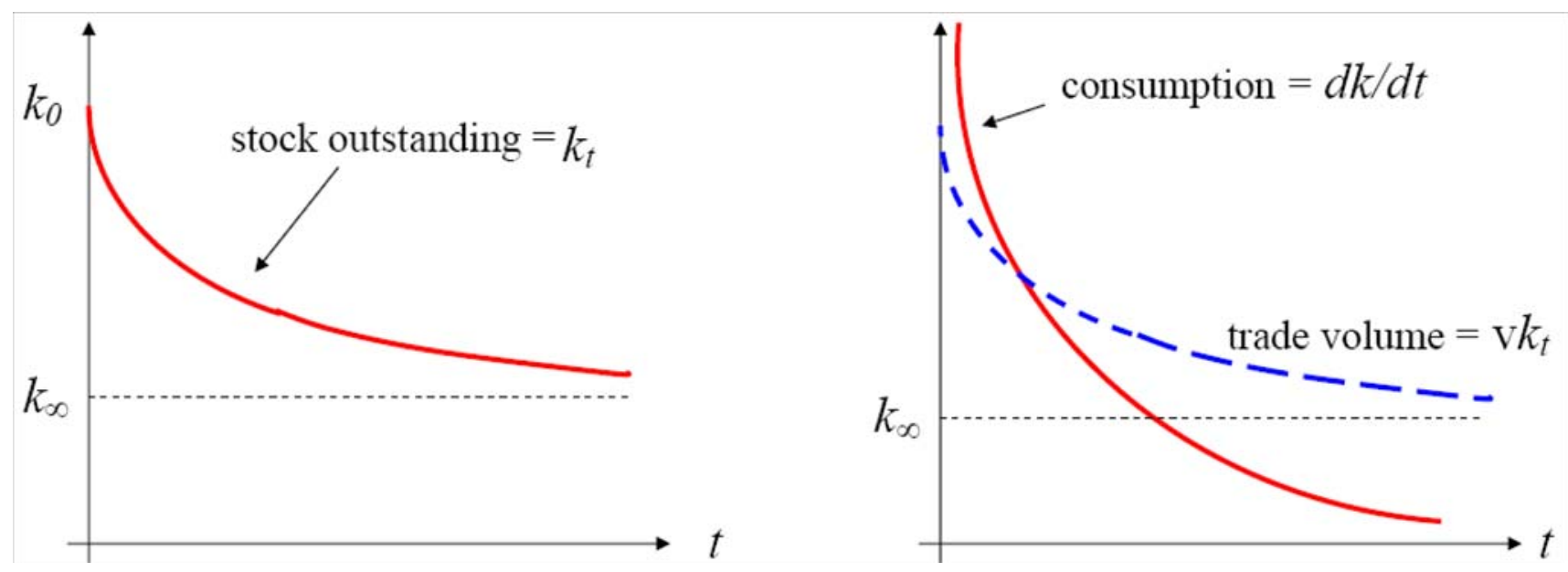

Figure 4: The Evolution of $k$, of CONSUMPtion And OF TRADing

period. ${ }^{8}$ Consumption approaches zero, whereas the stock held for speculative reasons remains positive. Optimal saving behavior dictates that this stock should occasionally change hands, and therefore we can detect bubbles by finding out whether the ratio of consumption to transactions for asset-holding purposes converges to zero. An example is solved in Section 4 and plotted in Figure 7.

Mixed strategy bubble equilibria.-The stocks $k_{c}$ and $k_{\infty}$ need not be distinguishable, and the owner of a unit of $k$ can, e.g., follow the mixed strategy "Sell a unit of $k$ to consumers with probability $\pi_{t}\left(p_{0}\right) d t$, where

$$
\pi_{t}\left(p_{0}\right) \equiv \frac{D\left(p_{0} e^{r t}\right)}{k_{0}}
$$

and where the realizations are independent over agents so that there is no aggregate risk. Every owner of capital follows the same mixed strategy. The end result is the same as in the pure strategy case, and we still have $p_{t}=p_{0} e^{r t}$ and no uncertainty at the market level. Therefore the observable implications will be for the time path of $k_{t}$ itself and for the consumption of $k$, and not about a division of $k_{t}$ into two stockpiles.

Stochastic-bubble equilibria.-Additional equilibria exist in which the aggregate bubble is random so that

$$
p_{t}=p_{0} e^{r t} z_{t},
$$

where $z_{t}$ is a random walk with zero drift. For instance, a bubble that gradually builds and occasionally bursts is also an equilibrium. A condition that the resource is never exhausted for any realization of the $\left(z_{t}\right)$ process is that

$$
p_{0} z_{t}>p_{0}^{H}
$$

\footnotetext{
${ }^{8}$ In the GE version of Section 5 , the equilibrium fraction of $k$ traded will be $v=1$, but for now let $v$ be any positive constant.
} 
along every sample path of $z_{t}$. When $p_{0}>p_{0}^{H}$, many such equilibria exist in the sense that there are many distributions of $z_{t}$ that have zero drift and that satisfy (6) for each realization of $\left(z_{t}\right)$.

\subsection{Robustness}

Let us check the robustness of our conclusions to five changes in the assumptions. ${ }^{9}$ A sixth, algebraically messier extension to many capital goods is done in Appendix 2. We shall find that the existence of bubbles is robust, but that the test implied by Figure 4 is sometimes not the way to detect them.

\subsubsection{Supply endogeneity}

Let the supply function for the asset at date $t$ be $S(p, t)$. In that case $k$ evolves as

$$
\frac{d k}{d t}=S(p, t)-D(p)
$$

Suppose that for every $p_{0} \geq 0,{ }^{10}$

$$
K\left(p_{0}\right) \equiv \int_{0}^{\infty} S\left(p_{0} e^{r t}, t\right) d t<\infty
$$

Condition (7) is met for any exhaustible resource. ${ }^{11}$ E.g., $S(p, t)=p^{\alpha} e^{-\gamma t}$ for $\gamma>r \alpha$ satisfies (7).

Now, the Hotelling equilibrium is a number $p_{0}^{H}$ such that

$$
k_{0}+K\left(p_{0}\right)=\int_{0}^{\infty} D\left(p_{0} e^{r t}\right) d t .
$$

As before, a bubble equilibrium is a price $p_{0}>p^{H}$, and the test for the equilibrium is the same - consumption goes to zero but the stock outstanding does not, just as in Figure 4.

\footnotetext{
${ }^{9}$ The fourth and fifth are also analyzed by Hotelling (1931).

${ }^{10} \mathrm{~A}$ model in which a bubble is explicitly defeated by supply is Deaton and Laroque (1992); in some periods agents store a fraction of the good, but in other periods they store none of it. The supply function in their model does not meet condition $(7)$ - the "harvests" add up to infinity.

${ }^{11}$ If at most $\bar{K}$ can ever be extracted, then

$$
\int_{0}^{\infty} S\left(p_{t}, t\right) d t \leq \bar{K} .
$$
}

for any $\left(p_{t}\right)_{0}^{\infty}$. 


\subsubsection{Depreciation of $k$}

Let $k$ depreciate so that

$$
\frac{d k}{d t}=-\delta k-x_{t}
$$

where $x_{t}$ is consumption. Bubble equilibria remain, but now $k_{t}$ must always converge to zero. Storage of wine now requires that price appreciate at $r+\delta$ :

$$
p_{t}=p_{0} e^{(r+\delta) t}
$$

We now have $x_{t}=D\left(p_{0} e^{(r+\delta) t}\right)$ for some unknown constant $p_{0}$. The solution to (8) for $k_{t}$ is

$$
k_{t}=e^{-\delta t} k_{0}-\int_{0}^{t} e^{-\delta(t-s)} D\left(p_{0} e^{(r+\delta) s}\right) d s .
$$

A "Hotelling equilibrium", $p_{0}^{H}$ should be the smallest $p_{0}$ for which $k_{t} \rightarrow 0$. Any smaller $p_{0}$ will cause $k_{t}$ to eventually become negative. Before solving for $p_{0}^{H}$ note that there is again a continuum of bubble equilibria indexed by $p_{0}>p_{0}^{H}$, but that now they all entail $k_{t} \rightarrow 0$. The simple test of the time-path of consumption relative to that of trading such as is depicted on the right panel in Figure 4 will not work.

EXAMPLE: $D(p)=p^{-\beta}$ with $\beta>1$ (the elastic demand case). Appendix 3 derives the Hotelling equilibrium to be

$$
p_{0}^{H}=\left(\frac{1}{k_{0}}\right)^{1 / \beta}\left(\frac{1}{\beta r+(\beta-1) \delta}\right)^{1 / \beta} .
$$

and the Hotelling sequence for $k_{t}$ is just

$$
k_{0} e^{-\beta(r+\delta) t}
$$

Because depreciation raises the growth rate of $p_{t}$ and because demand is elastic, holding $p_{0}$ constant, a higher $\delta$ reduces consumption by more than $\delta k$, and the net effect is to lower $p_{0}^{H}$. For $k_{0}=1, \beta=2$, and $r=\delta=0.1$, Figure 5 plots the evolution of $k$ in Hotelling's equilibrium and in a bubble equilibrium. It also plots an infeasible path for $k_{t}$, one that would be implied by a price lower than $p_{0}^{H}$.

\subsubsection{Convenience yield}

The owner of the asset may derive pleasure from holding it. Let utility depend on both consumption, $x$, storage, $k$. That is, let utility be $U(x, k)$, with $U$ increasing, differentiable, and concave in both of its arguments, and let $r$ be the discount rate $^{12}$. For now, assume that $\lim _{x \rightarrow 0} U_{x}=+\infty$, and to simplify further, consider a representative agent setup in which every agent chooses the same $(x, k)$ pair.

\footnotetext{
${ }^{12}$ which, in an economy with no growth, would equal the rate of interest.
} 


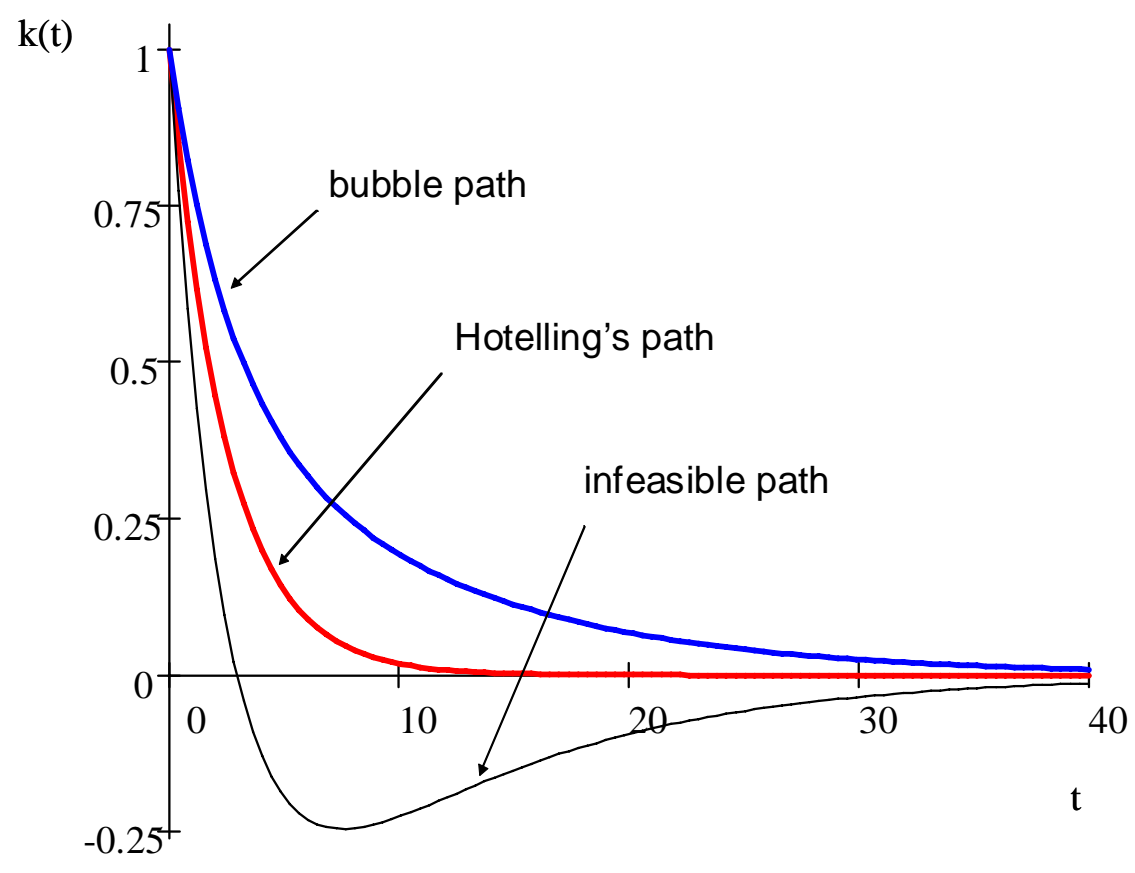

Figure 5: PATHS FOR $k_{t}$ WHEN $\delta>0$

The price of capital and the marginal utility of consuming another unit of it must, at each date, equal the marginal utility of lifetime storage:

$$
p_{t}=U_{x}\left(x_{t}, k_{t}\right)=\int_{t}^{\infty} e^{-r(s-t)} U_{k}\left(x_{s}, k_{s}\right) d s .
$$

Differentiating the RHS of (12) and applying (12) to the result, we have $\frac{d p}{d t}=$ $r U_{x}\left(x_{t}, k_{t}\right)-U_{k}\left(x_{t}, k_{t}\right)$, i.e., $p$ satisfies the ODE

$$
\frac{d p}{d t}=r p-U_{k}(x, k) .
$$

Therefore $p$ grows more slowly than at the rate $r$, and may even decline.

Equilibria are easier to explain if $U$ is additively separable. Let $U(x, k)=u(x)+$ $v(k)$ with both $u$ and $v$ increasing, concave, and differentiable. Then $p=u^{\prime}(x)$, and we have the pair of ODEs for $(p, k)$ given by

$$
\frac{d p}{d t}=r p-v^{\prime}(k),
$$

and

$$
\frac{d k}{d t}=-\left(u^{\prime}\right)^{-1}(p)
$$


To solve them we need two initial conditions. We are given $k_{0}$, but $p_{0}$ must be solved, as before, from the equation

$$
k_{0}-k_{\infty}=\int_{0}^{\infty} D\left(p_{0} e^{r t}\right) d t
$$

Hotelling's equilibrium obtains when $k_{\infty}=0$. The rest are bubble equilibria. ${ }^{13}$

Can convenience yield alone justify eternal storage in an equilibrium with no bubbles? Suppose that it could. Then some capital would be stored forever, i.e., it would not be consumed. Now if there were no bubble and if we ever did reach (even asymptotically) the point where we stored some $k$ eternally and would never again consume it, (12) would read

$$
p_{t} \rightarrow \frac{1}{r} v^{\prime}(k) .
$$

That is, $p_{t}$ would become constant. This simple model can therefore generate eternal storage, but not an endless price appreciation. Moreover, (14) could not hold if $u(x)$ satisfied an Inada condition.

\subsubsection{Monopoly power}

Hotelling works out the case where $k$ is owned by a monopolist. With no costs of storage, Hotelling argues that if the monopolist is willing to store some of the capital, his marginal revenue must grow at the rate of interest. That is to say,

$$
\frac{d}{d t} \ln \left(\frac{\partial}{\partial x} D^{-1}(x) x\right)=r
$$

To save space, we discuss equilibria only for the case of iso-elastic demand $x=D(p)=$ $p^{-\beta}$ with $\beta>1$. Then $D^{-1}(x)=x^{1-1 / \beta}$, and (15) reads,

$$
\frac{d}{d t} \frac{\partial}{\partial x} x^{(\beta-1) / \beta}=\left(\frac{\beta-1}{\beta}\right) \frac{d}{d t} x^{-1 / \beta}=\left(\frac{\beta-1}{\beta}\right) \frac{d p}{d t}=r,
$$

so that

$$
p_{t}=p_{0}+r t
$$

where $p_{0}$ solves

$$
k_{0}-k_{\infty}=\int_{0}^{\infty} D\left(p_{0}+r t\right) d t
$$

Again, Hotelling's equilibrium is the one where $k_{\infty}=0$. The rest are bubble equilibria.

\footnotetext{
${ }^{13}$ The Appendix briefly poses the Planner's problem in the context where identical agents derive utility from holding $k$ as well as consuming it.
} 
The monopolist likes bubbles. He would like to sell as little as possible to the public for consumption thereby raising $p_{0}$, and pass the rest of the stock to competitive asset holders. Indeed, if the monopolist moves first and chooses $p_{0}$, his total return is strictly increasing in $p_{0}$ and the problem has a solution unless we put a cap on willingness to pay as discussed in the next subsection. ${ }^{14}$

\subsubsection{Bounded willingness to pay}

Hotelling's works this case out too. Let $\bar{p}$ be maximal willingness to pay, so that $\bar{p}$ is the smallest $p$ for which

$$
D(p)=0 .
$$

We continue to assume that $D$ is continuous. Hotelling's equilibrium now entails exhaustion of the resources in finite time, $T$. Thus his equilibrium is a price path $p_{t}=p_{0}^{H} e^{r t}$ for $t \in\left[0, T^{H}\right]$, where $\left(p_{0}^{H}, T^{H}\right)$ solves the pair of equations

$$
k_{0}=\int_{0}^{T} D\left(p_{0} e^{r t}\right) d t
$$

and

$$
p_{0} e^{r T}=\bar{p}
$$

for $\left(p_{0}, T\right)$.

Bubble equilibria.-A bubble equilibrium is now the triple $\left(p_{0}, T, k_{\infty}\right)$ such that, instead of (18) (17), now solves (18) and

$$
k_{0}-k_{\infty}=\int_{0}^{T} D\left(p_{0} e^{r t}\right) d t
$$

for $k_{\infty} \in\left[0, k_{0}\right)$. As $\bar{p} \rightarrow \infty$ we recover the original equilibrium set.

\section{Application to wine}

Let us now apply the model to vintage wines. We shall assume that wine from a given chateau-(i.e., label-)vintage pair is homogeneous. Thus we interpret $k_{0}$ as, say, the total amount of the 1870 Lafite bottled in 1870. The stock is not renewable different vintages of a given wine are imperfect substitutes, judging by the vastly different prices at which they sell.

Each chateau has a monopoly on its wine which is regarded as distinct from other wines, but each vintage soon passes out of its hands ${ }^{15}$ and into the cellars of many

\footnotetext{
${ }^{14}$ Coase's conjecture - that a durable-goods monopolist loses his market power because he cannot commit to not lowering his price in future periods - does not apply here because the marginal cost of supplying the good jumps from zero to infinity at $k_{0}$.

15 except for a stock that a chateau may keep to re-top old bottles, although this practice is in decline because re-topped bottles look more like counterfeits.
} 
dealers, restaurants and private individuals, so that the chateau can focus on producing its next vintage. As of then, the competitive model seems to be appropriate.

In the model, $k$ is homogeneous whereas, in fact, even within a vintage-chateau pair there is significant heterogeneity that can be detected by inspection and that therefore affects prices at which the bottles sell. The buyer has two main concerns: Is the bottle authentic, and has it been properly stored. ${ }^{16}$ Thus the series in Figure 1, or in the Figures in the Appendix, do not all represent the movement in the prices of a claim to a given bottle, although as the vintage becomes old, it is ever more likely that the same bottle appears on a restaurant's wine list or a dealer's list, and ever more likely that the same bottles will be traded again and again at auction.

The model states that the prices of some of the wines may contain bubbles. Can we detect any? Suppose that in Figure $4, k_{\infty}$ is positive. If there is a bubble, consumption should gradually taper off but that trading should continue indefinitely. By contrast, if there is no bubble, all trade should taper off together with consumption. If $k$ depreciates (Sec. 2.1.2), then in the absence of a bubble, consumption and trade should decline together. Either way, if we see trading without consumption, we may infer that a bubble exists.

To check this, it would be ideal to have data on how much of a particular wine is stored, and on how much of that wine is being consumed. Unfortunately, we do not have such data. We shall therefore try to infer these magnitudes indirectly from the frequencies with which a wine is offered for sale in three different modes - by auctions, by dealers, and by restaurants. A wine sold by a dealer or by a restaurant is usually consumed. By contrast, the sale of a wine at auction is likely to be stored. We can thus hope to learn how much of a particular wine is consumed and how much of it is stored, by comparing the frequency with which the wine is offered for sale at these three venues.

Age distributions. - Figure 6 shows the age distribution of wine offered for sale by dealers and restaurants, and wine actually sold at auction (we have transactions only for auctions). Until a few years ago, vintage wines were sold mainly at auction and not by dealers. ${ }^{17}$ Not surprisingly, therefore, the wines offered for sale by dealers are considerably younger than those sold at auctions. On the other hand, the wines offered for sale at restaurants are significantly older than the ones sold at auction.

\footnotetext{
${ }^{16}$ Some bottles were stored improperly which affects the level of the wine in the bottle and the sedimentation, some bottles are stored by reputable dealers and some not, some have a reputable distributors and some not, some have been re-corked or "reconditioned" and some not, etc.. Counterfeiting is on the rise for the old, valuable vintages. See Mariani (2007), Gekas (2007) and Winesearcher (2007) for more on fake wines and how to recognize them.

${ }^{17}$ Market structure has been changing recently and dealers have started to hold auctions. Dealers now offer wines that they do not necessarily store themselves. The oldness of the vintages offered for sale today by the Antique Wine Company and described in Figure 2 is a new phenomenon. For most of the 20th Century, one of the world's most prestigeous dalers, Berry Brothers \& Rudd, offered wines that were at most 40 years old.
} 

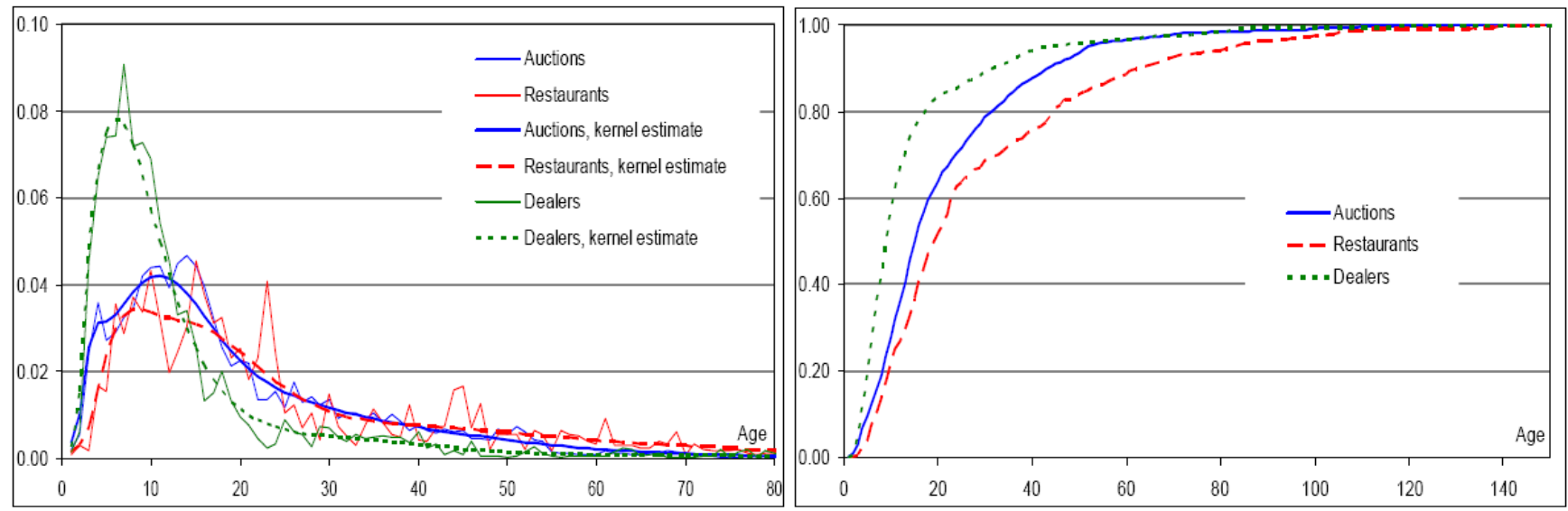

Figure 6: Ages of Wines offered by Auctions, Dealers, and Restaurants.

We cannot take the restaurant numbers at face value, however. First, while auctions prices are transactions prices, the dealer and restaurant prices are list prices. A vintage wine will often appear on a restaurant's wine list without ever being sold. Therefore neither the restaurant nor the dealer age distributions pertain to the distribution of ages of wine actually consumed. Second, even as a distribution of listed prices, the restaurant data are biased towards the older vintages because (in contrast to a dealer's list) a restaurant wine list typically does not provide a wine's vintage for the young wines. The unidentified vintages were excluded from the data which, therefore, heavily oversample the older vintages. Therefore, while the restaurant age distributions lie to the right of those for auction sales, this does not prove that the wines consumed in restaurants are older than those traded at auction. The reverse is almost certainly true.

Convenience yield, again.-Why would restaurants hold on to wine that they do not sell? Is there a convenience yield on old wine (see Sec. 2.1.3)? As it ages, wine undoubtedly acquires the status of a collectible, of an antique. This convenience yield is almost surely highest among restaurants. Indeed, the sommelier of a famous New York restaurant said this about the most expensive wines on his wine list: "I don't want to sell this wine. It makes the list look better." Is this a restatement of (14)? Moreover, (14) could hold if old wine is undrinkable and hence cannot have a large $u^{\prime}(0)$. We noted, however, that (14) fails empirically since in fact the prices of the oldest wines continue to rise. ${ }^{18}$ Therefore convenience yield alone is probably not strong enough a motive to explain why restaurants store old wine. Rather, old wine appears to be an asset that the restaurant holds, and on which there is a bubble. ${ }^{19}$

\footnotetext{
${ }^{18}$ To generate a rising price one needs to assume that $v^{\prime}(k)$ rises directly as a function of the age of $k$ age, and not just as a function of its scarcity.

${ }^{19}$ But the case is not proved beyond reasonable doubt. LeRoy (2004) discusses these issues in an
} 


\subsection{Standard tests for bubbles}

Standard tests for bubbles on an asset compare the asset's price to the stream of earnings to which it is a claim. I shall not be able to carry out such a test, but it is worth outlining what information such a test would require.

Let us return to (4). The fundamental at date $t$ is the expected discounted dividend, $p_{s}$, conditional on information available at date $t$ :

$$
f_{t}=\frac{\int_{t}^{\infty} e^{-r(s-t)} \pi_{s} p_{s} d s}{1-\int_{0}^{t} \pi_{s} d s}=\frac{\int_{t}^{\infty} \pi_{s} d s}{1-\int_{0}^{t} \pi_{s} d s} p_{t},
$$

with $\pi_{t}$ defined in (4). If we define the bubble in the standard way (see LeRoy 2004) as $b_{t} \equiv p_{t}-f_{t}$, we obtain

$$
b_{t}=\frac{1-\int_{0}^{\infty} \pi_{s} d s}{1-\int_{0}^{t} \pi_{s} d s} p_{t}
$$

Conditional on not bursting the bubble must rise faster than the rate of interest:

$$
\frac{1}{b} \frac{d b}{d t}=\frac{1}{p} \frac{d p}{d t}+\frac{\pi_{t}}{\left(1-\int_{0}^{t} \pi_{s} d s\right)^{2}}=r+h_{t},
$$

where $h_{t} \equiv \pi_{t} /\left(1-\int_{0}^{t} \pi_{s} d s\right)$ is the hazard rate of a wine sale. The point is that if a unit of the capital is consumed, the bubble attached to the price of that unit alone bursts. (Of course the price of the remaining units of capital continues to rise). Hence the bubble must rise fast enough to compensate for the loss of the value that occurs in the event that the particular unit of capital is consumed. In expectation, however, the bubble still grows at the rate of interest:

$$
E_{0} b_{t}=\left(b_{0} e^{r t+\int_{0}^{t} h_{s} d s}\right) \int_{t}^{\infty} \pi_{s} d s=b_{0} e^{r t}
$$

because $\int_{t}^{\infty} \pi_{s} d s=\exp \left(-\int_{0}^{t} h_{s} d s\right)$.

From (21) we find that the bubble exists if $\int_{0}^{\infty} \pi_{s}<1$. From (4) we see that we can detect a bubble path with certainty only if we know the shape of the demand curve at extremely high prices, prices that have not yet been reached. Therefore, even if we observe $k_{t}$ we cannot tell in finite time if we are seeing a bubble. One must assume something about the shape of demand before one can infer the presence of a bubble. We do not, however, have the consumption data needed to estimate $\pi$.

Feedback from asset prices to fundamentals. - If a bubble forms, it raises $p_{0}$ and, hence, $p_{t}$, and therefore there is a feedback from asset prices to fundamentals in the general sense of Timmermann (1994), though the effect here is nonlinear. A bubble

insigtful way. 
forms, reducing $k_{c}$. This raises $p_{0}$ which, in turn, raises the fundamental value of the asset $e^{-r t} p_{t}$. But a vintage may have a high $p_{0}$ because it has a bubble on it, or because it is of high quality so that the willingness to pay is higher. Therefore as with other assets generally, high prices may signify a bubble or high fundamentals.

The give-away fact is quantity consumed relative to the quantity stored. High prices due to fundamentals (a high demand or a low $k_{0}$ ) should not be associated with a higher survival of $k$, whereas high prices due to bubbles should be. That was the main message of Figure 4. To sum up, evidence shows that it is high priced wines like the Bordeaux wines in my sample that survive a long time and continue to be traded. Low-priced wines disappear rather quickly. This indicates that these wines acquire the properties of an asset to be held as an investment rather than as a consumable item. ${ }^{20}$

\section{General equilibrium}

So far we have assumed that a rational bubble can exist in the economy at large. This depends on whether agents are willing to save enough so that they will be willing to hold the wealth that the bubble creates. We now derive conditions under which the bubble can survive. The condition is the second inequality in (31) and it implies the Santos-Woodford (1997) condition that the present value of aggregate consumption must be infinite. Thus there are no new results here for the general theory of bubbles, only a demonstration that the arguments of Section 2 can be embedded into a GE framework. The conditions can be weakened if there is a convenience yield on storing $k$, but that too corresponds to results on bubbles on money when money enters the utility function

This part of is more easily done in discrete time; the parallels to the previous sections will be obvious. Aside from $k$, we now assume that there is a second perishable good, $y$, which can be produced at constant returns to scale using labor only, and which acts as the numeraire. We shall assume a growing population of two-periodlived agents. The only asset ${ }^{21}$ and the only durable good is $k$, and its initial stock is held by the date-zero old generation. There are no bequests.

Population grows each period by the factor $n>1$. Each agent has a unit labor endowment when young. Consumption of $k$ occurs when old. Leisure does not enter

\footnotetext{
${ }^{20}$ One person in the trade did not agree with the thrust of these conclusions, and recently said this: "In the past week I have drunk 1978 Meursault Perrieres Comte Lafon, 1992 Montrachet Baron Thenard, 1964 Chateau Petrus and 1975 Chateau d'Yquem, and on Tuesday we will drink a 1949 Burgundy.....While there clearly are a few men buying wine as an investment, most wine collectors at least initially plan to drink all the wine they buy. The problem is that the typical wine collector has no self control and quickly buys more than he can ever drink, thus becoming what I term 'an inadvertent wine investor', since at some point he will be forced to sell some of his surplus wine."

${ }^{21}$ With a second asset like bonds or fiat money, a bubble on $k$ would, in addition to displacing some consumption of $k$, also displace a portion of the second asset.
} 
the utility function. An agent born at date $t$ has lifetime utility

$$
c_{t}+\beta\left(c_{t+1}+U\left[x_{t+1}\right]\right)
$$

where $c_{t}$ and $c_{t+1}$ denote his consumption of $y$ in youth and old age, and $x$ is his consumption of capital. The linearity of utility in $c$ delivers a constant interest rate which simplifies the algebra but otherwise is inessential for the results. At date $t=0$ the young and old agents are both of measure one (this simplifies the notation), and the young population at $t$ is $n^{t}$. This too is the labor supplied inelastically at that date. Thus population begins to grow at date 1 .

The perishable good is produced with the technology

$$
y=w_{t} L
$$

where $w_{t}=w_{0} \gamma^{t}$ and where $L$ is labor services employed. With full employment we have

$$
y_{t}=w_{0}(\gamma n)^{t}
$$

Prices.-The numeraire is $y$. In terms of $y$ the gross rate of interest must be $\beta^{-1}$. Let $p$ be the price of $k$. Technology (23) is operated by competitive firms who bid the wage up to $w_{t}$.

Assets.-Assume $K_{t}$ is the only asset. It evolves as

$$
K_{t+1}=K_{t}-n^{t} x_{t}
$$

where $x_{t}=\left(U^{\prime}\right)^{-1}\left(p_{t}\right)$. The young must buy capital if they are to consume in old age. Define capital per young person to be $k_{t}=n^{-t} K_{t}$. Then $p_{t} k_{t}=\#$ of units of $y_{t}$ you can buy with the capital, and you paid $p_{t-1} k_{t}$ for it at date $t-1$.

Resource constraint: Consumption of $y$ per old agent (there are $n^{t}$ ) of them must equal output per old agent

$$
c_{t}^{o}+n c_{t}^{y}=n w_{t}
$$

Budget constraint of young:

$$
p_{t} k_{t+1}+c_{t}^{y}=w_{t}
$$

Budget constraint of old:

$$
p_{t} k_{t}=c_{t}^{o}+p_{t} x_{t} .
$$


Analysis: Solve (26) for $c_{t}^{y}=w_{t}-\frac{1}{n} c_{t}^{o}$ and substitute into (27) to get

$$
p_{t} k_{t+1}=\frac{1}{n} c_{t}^{o}
$$

and using (28) to eliminate $c_{t}^{o}$ we end up with the difference equation of the debt per old member

$$
k_{t+1}=\frac{1}{n}\left(k_{t}-x_{t}\right)
$$

This seems to be consistent with (25) - if we multiply $n^{t+1}$ and apply the definition of $k_{t}$.

Willingness to hold the asset.-The entire stock $k_{t}$ must change hands each period without inducing negative $c_{t}^{y}$. This means that we need

$$
p_{t} k_{t+1} \leq w_{t}
$$

In (25) we have

$$
K_{t+1}=K_{t}-n^{t}\left(U^{\prime}\right)^{-1}\left(p_{0} \beta^{-t}\right)
$$

\subsection{Example}

In the following example, $K_{t}$ will converge to its limit geometrically. For $\sigma>0$, take

$$
U(x)=\frac{x^{1-1 / \sigma}-1}{1-1 / \sigma} \Longrightarrow U^{\prime}(x)=x^{-1 / \sigma} \Longrightarrow\left(U^{\prime}\right)^{-1}(p)=p^{-\sigma}
$$

Then (30) reads $K_{t+1}=K_{t}-p_{0}^{-\sigma}\left(\beta^{\sigma} n\right)^{t}$. We shall assume that

$$
\beta^{\sigma} n<1<\beta n \gamma
$$

The first inequality in (31) guarantees that it has the solution

$$
K_{t}=K_{\infty}+\left(\beta^{\sigma} n\right)^{t}\left(K_{0}-K_{\infty}\right),
$$

which is indexed by $K_{\infty}$. The Hotelling equilibrium has $K_{\infty}=0$ and the Hotelling solution therefore simplifies to

$$
K_{t}^{H}=\left(\beta^{\sigma} n\right)^{t} K_{0}
$$

The convergence of $K_{t}$ to $K_{\infty}$ is geometric. The higher is $K_{\infty}$, the higher is $p_{0}$ :

$$
p_{0}=\left(\left[1-\beta^{\sigma} n\right]\left[K_{0}-K_{\infty}\right]\right)^{-1 / \sigma} .
$$

The savings constraint.- Extremely high values of $K_{\infty}$ will not be feasible, however, because the young will not be able to absorb the bubble. Since $k_{t} \leq K_{0} / n^{t}$, the second inequality in (31) guarantees that (29) will hold if

$$
p_{0} K_{0}(n \beta)^{-t} \leq w_{0} \gamma^{t} .
$$




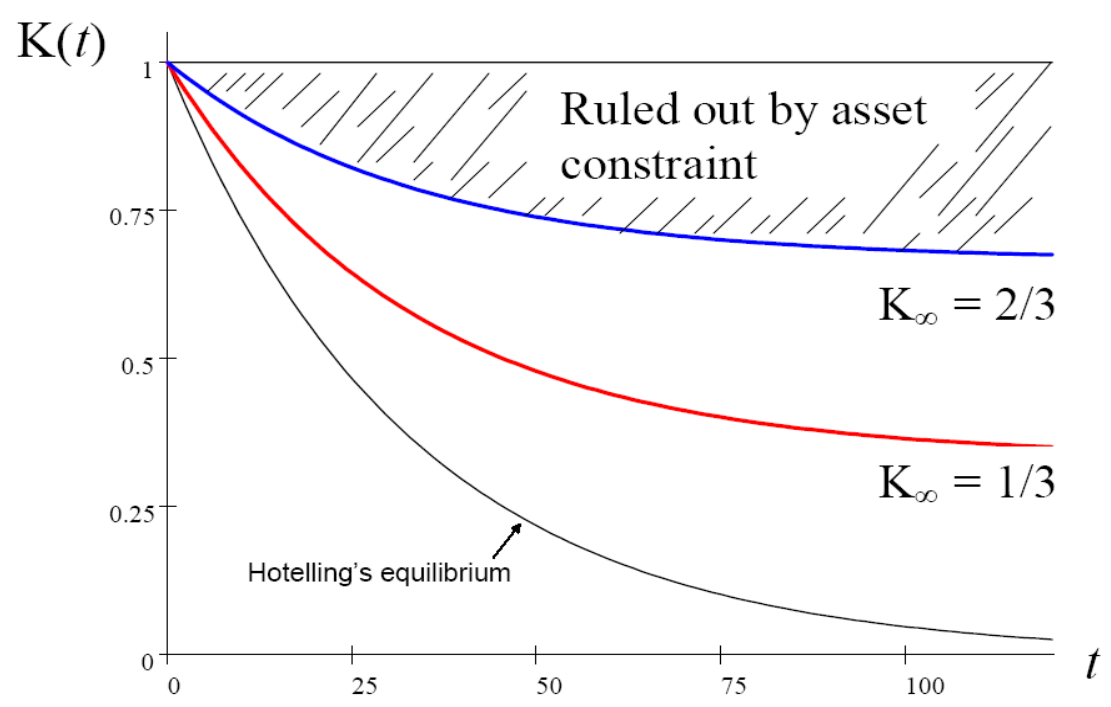

Figure 7: The SET OF EQUILIBRIA

In light of (31), it is necessary and sufficient that

$$
p_{0} K_{0} \leq w_{0}
$$

The per-capita date-zero value of capital is less than the initial wage. Substituting from (32) the condition reads

$$
\frac{K_{\infty}}{K_{0}} \leq 1-\frac{K_{0}^{\sigma-1}}{\left(1-\beta^{\sigma} n\right) w_{0}^{\sigma}} .
$$

If $\sigma=1,(34)$ reads

$$
\frac{K_{\infty}}{K_{0}} \leq 1-\frac{1}{(1-\beta n) w_{0}}
$$

Simulated example.-Set $K_{0}=\sigma=1, \beta n=0.97$. Then The Hotelling equilibrium has $K_{t}^{H}=(0.97)^{t}$. The worst equilibrium has $K_{t}=1$ for all $t$. Figure 7 plots the solution for $K_{\infty}=\frac{1}{3}$ (red line) and $K_{\infty}=\frac{2}{3}$ (blue line). But (34) now reads

$$
K_{\infty} \leq 1-\frac{1}{(0.03) w_{0}^{\sigma}} .
$$

and so a constant-interest-rate Hotelling equilibrium exists only if $w_{0}>(0.03)^{-1}$. The larger is $w_{0}$, the larger $K_{\infty}$ can be, and the larger the number of bubble equilibria that exist. As $w_{0}$ gets large, all the equilibria plotted in Figure 7 will exist, i.e., those for which $K_{\infty} \in[0,1)$. The "worst equilibrium" does not exist, for $K_{\infty}=1$ would 
require that $p_{0}$ be literally infinite. Figure 7 assumes that $w_{0}=100^{1 / \sigma}$ in which case (33) implies that $K_{\infty} \leq 2 / 3$.

Relation to the commodity-money literature.-At each date, the value of $k$ equals its intrinsic value. This follows from the Inada condition on $U$ that delivers an unbounded willingness to pay for consuming $k$. If $U^{\prime}$ was bounded, all consumption of $K$ would eventually cease, and the remaining stock would serve as the asset. Similar conclusions hold in the OG model of Sargent-Wallace (1983, Sec. 3.3) for the case in which gold cannot be produced and in which population grows for ever. ${ }^{22}$

\subsection{Welfare}

Bubbles can arise even though the no-bubble equilibrium - the Hotelling equilibrium - is Pareto optimal. The Planner discounts generations at the rate $\beta$ and has an infinite horizon. He will fully employ the available labor and distribute the output among agents - any distribution of $y_{t}$ over agents yields the Planner the same utility. Since the Planner's decisions about $y$ do not interact with his decisions about $x$, we can study the latter on its own. With $K_{0}$ given, the Planner then maximizes $\sum_{t=0}^{\infty}(\beta n)^{t} U\left(x_{t}\right)$ subject to $(25)$. That is, he solves

$$
\max _{\left(K_{t}\right)} \sum_{t=0}^{\infty}(\beta n)^{t} U\left(n^{-t}\left[K_{t}-K_{t+1}\right]\right)
$$

with $K_{0}$ given. The first-order condition is

$$
U^{\prime}\left(x_{t}\right)=\beta U^{\prime}\left(x_{t+1}\right)
$$

and it is also necessary that the Planner not waste any capital, i.e., that

$$
\lim _{t \rightarrow \infty} K_{t}=0
$$

But this is just Hotelling's equilibrium in which all capital is exhausted.

Bubbles raise the utility of the date-zero old, and reduces the lifetime utility of every subsequent generation. A feasible Pareto improvement exists, however, in that $K_{\infty}$ could be consumed at some dates without reducing any generation's consumption of $x$ and $y$. This conclusion echoes those in the commodity-money literature.

\section{Conclusion}

When it comes to bubbles on a consumable exhaustible resource, two things are special. First, it is easier for the bubble to form and, second, detecting the bubble

\footnotetext{
${ }^{22}$ Champ and Freeman (1994, Ch. 2) model such a situation but without population growth, in which case the demand for assets is bounded as, therefore, also is the price of gold.
} 
is easier, requiring simply that consumption not converge to zero when compared to trading in the asset. Using this simple test, we have found that it is quite likely that bubbles on some vintage wines exist because trading in these old wines continues, and the rate at which they are consumed is quite low.

Can the model apply to certain other assets? Closest to this is oil, though we would need to add an extraction cost. Oil fits the two key assumption that the reserves of $k$ are bounded and that $k$ is consumable. Land is in fixed supply but is not consumed, and the same is true of art and other collectibles. Gold, and silver have a significant salvage value even after being converted into jewelry, so it is really better thought of as an asset that carries a large convenience yield that lowers its equilibrium return to zero or less.

\section{References}

[1] Ashenfelter, Orley; Kathryn Graddy. "Auctions and the Price of Art." J. Econ. Literature 41, no. 3 (Sep. 2003): 763-787.

[2] Burton, Benjamin and Joyce Jacobsen. "Measuring Returns on Investment in Collectibles." J. Econ. Perspectives 13, no. 4 (Aut. 1999): 192-212.

[3] quiry 39 , no. 3 (Jul. 2001): 337-350.

[4] Champ, Bruce and Scott Freeman. Modeling Monetary Economies. New York: Wiley 1994.

[5] Dasgupta, Partha and Geoffrey Heal. Economic Theory and Exhaustible Resources. Cambridge: Cambridge University Press, 1979.

[6] Deaton, Angus and Guy Laroque. "On the Behaviour of Commodity Prices." Review of Economic Studies 59, no. 1 (January 1992): 1-23.

[7] Gekas, Alexandra. "Wine Cops, on the Case." Newsweek March 9, 2007.

[8] Hotelling, Harold. "The Economics of Exhaustible Resources." J. Polit. Econ. 39, no. 2 (Apr. 1931): 137-175.

[9] Jovanovic, Boyan. "Fitness and Age." J. Econ. Literature 39 (2001).

[10] Leroy, Steven. "Rational Exuberance." J. Econ. Literature 42 (September 2004): 783-804.

[11] Mariani, John. "What You Need to Know When Buying Wine at Auction." Bloomberg (2007). 
[12] Santos, Manuel and Michael Woodford. "Rational Asset Pricing Bubbles." Econometrica 65, no. 1 (Jan. 1997): 19-57.

[13] Sargent, Thomas and Neil Wallace. "A Model of Commodity Money." Journal of Monetary Economics 12 (1983): 163-87.

[14] Timmermann, Alan. "Present Value Models with Feedback : Solutions, Stability, Bubbles, and Some Empirical Evidence." J. Econ. Dynamics $\&$ Control 18, no. 6 (Nov. 1994): 1093-1119.

[15] Tirole, Jean. "Asset Bubbles and Overlapping Generations." Econometrica 53, no. 5 (Sep. 1985): 1071-1100.

[16] Winesearcher. "Counterfeits and Other Problems." 2007 http://www.winesearcher.com/fakes.lml 


\section{Appendix 1: The data}

The data include only incomplete histories of the various wines. Each data point includes: label, vintage, year offered for sale, quantity, size, price and currency. Three kinds of prices were collected:

1. Auctions.-1766-2007. About 100,000 observations. All are transactions prices.

2. Dealers.-Mid 1800s-2007. About 4,000 observations. For the 19th century, main source is the Guildhall Library, London. For most of the 20th Century, Berry Brothers and Rudd, London, and on-line sources. All are list prices.

3. Restaurants.-Mid 1800s-2007. About 5000 observations. For the pre-WW2 period, main source is the NY Historical Society. A handful from the U.S. Library of Congress and the NY Public Library. All are list prices.

Wines included.-Only 9 Chateau wines were selected: Haut Brion (1), Lafite Rothschild (2), Latour (3), Margaux (4), Mouton Rothschild (5), Ausone (6), Cheval Blanc (7), Petrus (8), D'Yquem (9). All are from the Bordeau region in France which, for the past 200 years has supplied most of the highest-priced wines.

No data are available on the stock of wine by vintage. 
Main data sources and \# observations

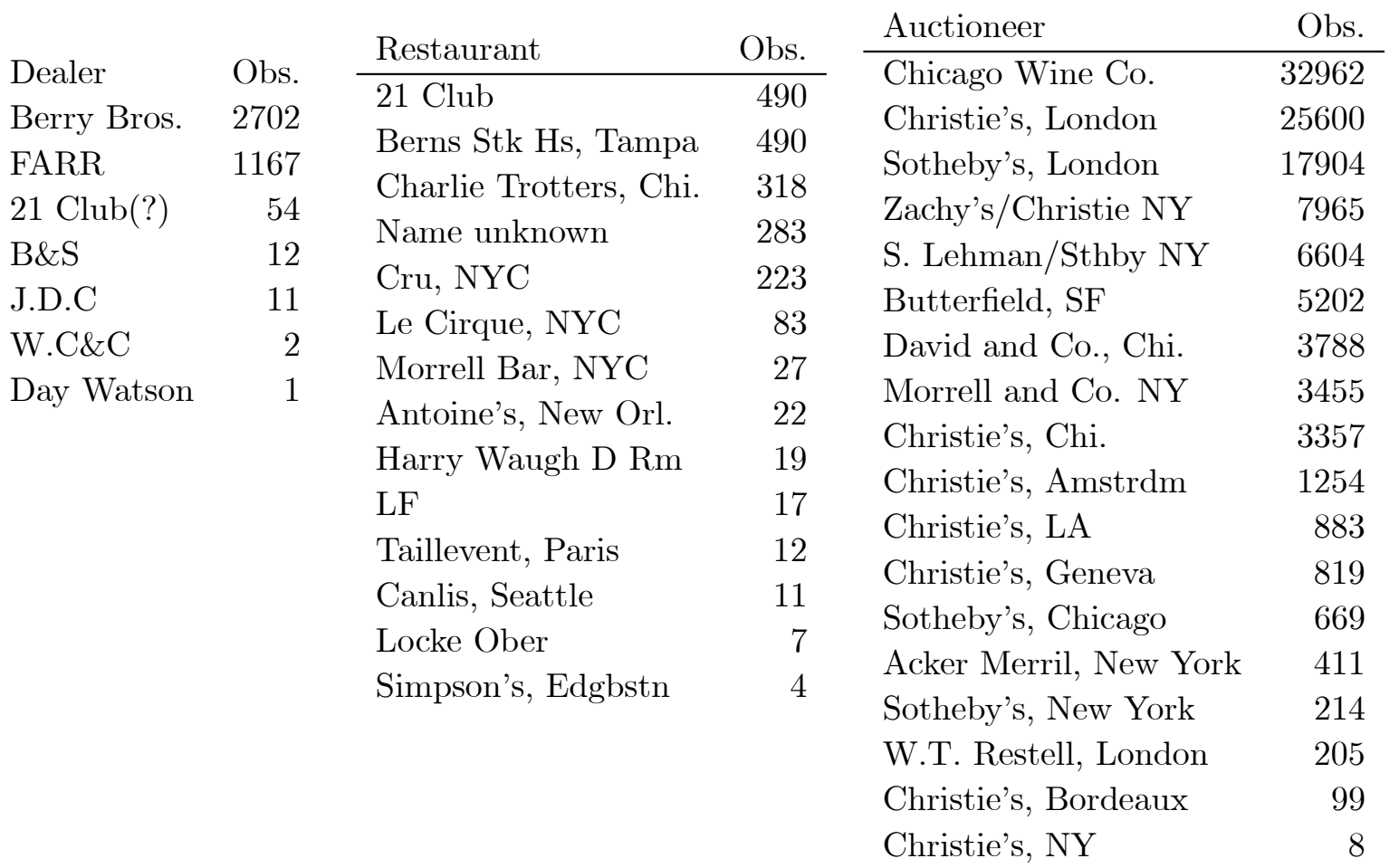

Conversion table. - All prices are per bottle and in year-2000\$ U.S. The conversion between different-sized bottles is described in the following table:

\begin{tabular}{|l|c|l|}
\hline Code & Conversion & Description \\
\hline $\mathrm{B}$ & 1.0 & Bottle \\
$\mathrm{M}$ & 2.0 & Magnum \\
$\mathrm{DM}$ & 4.0 & Double magnum \\
$\mathrm{IP}$ & 0.0 & Imperial pint \\
$\mathrm{MJ}$ & 3.0 & Marie-Jeanne \\
$\mathrm{TM}$ & 6.0 & Triple magnum \\
$\mathrm{QM}$ & 8.0 & Quadruple magnum \\
$\mathrm{J}$ & 6.0 & Jeroboam \\
$\mathrm{R}$ & 6.0 & Rehaboam \\
$\mathrm{I}$ & 8.0 & Imperial \\
$1 / 10$ & 0.5 & One-tenth (of a gallon) \\
$\mathrm{H}$ & 0.5 & Half bottle \\
$1 / 5$ & 1.0 & One-fifth (of a gallon) \\
Pint & 0.5 & Pint \\
\hline
\end{tabular}




\subsection{The history of the 1870 Lafite-Rothschild}

A major concern with a wine that old is that it is undrinkable, that it has "turned into vinegar." But the evidence is that if properly stored, wines retain their quality even after they are 100 years old. Notes on some recent tastings are at http://www.vintagetastings.com/.

The last known (to me) tasting of the 1870 Lafite was in 1970, and was organized by Michael Broadbent, the then head of Christie's wine department. Describing his experience of tasting the 1870 Lafite at age 100, Broadbent said: "I am very often asked by journalists which is my favorite wine. This, I believe, is the most spectacular and memorable one." A detailed write-up of the event is at http://www.empireclubfoundation.com/details.asp?. A more recent, 2002 tasting of an 1870 Château Cos d'Estournel (not in my sample) showed that the flavor was still good.

The following three tables provide the details of each data point in Figure 1. For some years, more than one auction- and restaurant-price observation was available. In that case, the observations were averaged for the purpose of the plot.

Following the tables documenting the history of the 1870 Lafite, we shall display a collection of plots for certain other vintages and other labels. The Table and the plots should provide a fairly accurate feel for the kind of coverage that the data provide, and for the patterns that these data show. 
The 1870 Château Lafite-Rothschild

AUCTIONS

\begin{tabular}{|l|r|r|r|r|}
\hline Auction & Loc & Year & Age & Price \\
\hline Christie's, London & UK & 1889 & 19 & 22 \\
Christie's, London & UK & 1889 & 19 & 17 \\
Christie's, London & UK & 1892 & 22 & 17 \\
Christie's, London & UK & 1895 & 25 & 23 \\
Christie's, London & UK & 1895 & 25 & 22 \\
Christie's, London & UK & 1895 & 25 & 19 \\
Christie's, London & UK & 1896 & 26 & 19 \\
Christie's, London & UK & 1908 & 38 & 21 \\
Christie's, London & UK & 1937 & 67 & 52 \\
Restell, London & UK & 1941 & 71 & 905 \\
Christie's, London & UK & 1971 & 101 & 341 \\
Christie's, London & UK & 1973 & 103 & 675 \\
Christie's, London & UK & 1976 & 106 & 696 \\
Christie's, London & UK & 1977 & 107 & 1809 \\
Christie's, London & UK & 1978 & 108 & 1747 \\
Butterfield and Butterfield & US & 1989 & 119 & 660 \\
Butterfield and Butterfield & US & 1989 & 119 & 903 \\
Sotheby's, London & UK & 1990 & 120 & 643 \\
Christie's, London & UK & 1990 & 120 & 316 \\
Christie's, London & UK & 1990 & 120 & 1248 \\
Christie's, London & UK & 1990 & 120 & 3626 \\
Christie's, London & UK & 1991 & 121 & 580 \\
Christie's, Chicago & US & 1991 & 121 & 1011 \\
Christie's, London & UK & 1992 & 122 & 302 \\
Christie's, London & UK & 1993 & 123 & 894 \\
Christie's, London & UK & 1993 & 123 & 894 \\
Christie's, London & UK & 1993 & 123 & 894 \\
Christie's, London & UK & 1993 & 123 & 894 \\
Christie's, London & UK & 1993 & 123 & 894 \\
David \& Co. & US & 1994 & 124 & 2789 \\
David \& Co. & US & 1994 & 124 & 2789 \\
David \& Co. & US & 1995 & 125 & 3616 \\
Christie's, New York & 1995 & 125 & 3955 \\
David \& Co. & 1995 & 125 & 3616 \\
The Chicago Wine Company & US & 1996 & 126 & 1866 \\
Christie's, London & UK & 1996 & 126 & 2055 \\
Christie's, London & 126 & 2055 \\
Sherry Lehman/Sotheby's & 127 & 2468 \\
\hline
\end{tabular}




\begin{tabular}{|l|c|c|c|r|}
\hline Auction & Loc & Year & Age & Price \\
\hline Morrell \& Co. & US & 1997 & 127 & 9656 \\
Zachy's/Christie's & US & 1998 & 128 & 1336 \\
Morrell \& Co. & US & 1998 & 128 & 11621 \\
Zachy's/Christie's & US & 1998 & 128 & 3645 \\
Sherry Lehman/Sotheby's & US & 1998 & 128 & 2219 \\
Morrell \& Co. & US & 1998 & 128 & 11621 \\
Christie's, London & UK & 1999 & 129 & 8434 \\
Christie's, London & UK & 1999 & 129 & 1756 \\
Zachy's/Christie's & US & 1999 & 129 & 3101 \\
Christie's, London & UK & 1999 & 129 & 6689 \\
Sherry Lehman/Sotheby's & US & 1999 & 129 & 5685 \\
Zachy's/Christie's & US & 1999 & 129 & 3101 \\
Sherry Lehman/Sotheby's & US & 1999 & 129 & 2247 \\
The Chicago Wine Company & US & 2000 & 130 & 5200 \\
The Chicago Wine Company & US & 2001 & 131 & 7195 \\
Zachy's/Christie's & US & 2006 & 136 & 3611 \\
Zachy's/Christie's & US & 2006 & 136 & 20063 \\
Christie's, London & UK & 2006 & 136 & 7507 \\
\hline
\end{tabular}

The 1870 Lafite - RESTAURANTS

\begin{tabular}{|l|c|r|r|r|}
\hline Restaurant & Loc & Year & Age & Price \\
\hline Fest-Essen, Dusseldorf & GE & 1889 & 19 & 32 \\
CentralStelle, Dusseldorf & GE & 1895 & 25 & 35 \\
Charlie Trotters, Chicago & US & 2003 & 133 & 7931 \\
Charlie Trotters, Chicago & US & 2003 & 133 & 8891 \\
Charlie Trotters, Chicago & US & 2004 & 134 & 8660 \\
Charlie Trotters, Chicago & US & 2004 & 134 & 7726 \\
Charlie Trotters, Chicago & US & 2005 & 135 & 7367 \\
Charlie Trotters, Chicago & US & 2005 & 135 & 8258 \\
Charlie Trotters, Chicago & US & 2006 & 136 & 8111 \\
Charlie Trotters, Chicago & US & 2006 & 136 & 7235 \\
Charlie Trotters, Chicago & US & 2006 & 136 & 8111 \\
Charlie Trotters, Chicago & US & 2007 & 137 & 12806 \\
Charlie Trotters, Chicago & US & 2007 & 137 & 14941 \\
\hline
\end{tabular}

The 1870 Lafite - DEALERS

\begin{tabular}{|c|c|c|c|c|c|}
\hline Dealer & & Loc & Year & Age & Price \\
\hline Day Watson & \multirow{7}{*}{26} & UK & 1873 & 3 & 22 \\
\hline Berry Bros. \& Rudd & & UK & 1907 & 37 & 583 \\
\hline Berry Bros. \& Rudd & & UK & 1928 & 58 & 980 \\
\hline Berry Bros. \& Rudd & & UK & 1932 & 62 & 771 \\
\hline Berry Bros. \& Rudd & & UK & 1935 & 65 & 1232 \\
\hline Berry Bros. \& Rudd & & UK & 1937 & 67 & 1182 \\
\hline CellarBrokers.com & & US & 2007 & 137 & 9074 \\
\hline
\end{tabular}



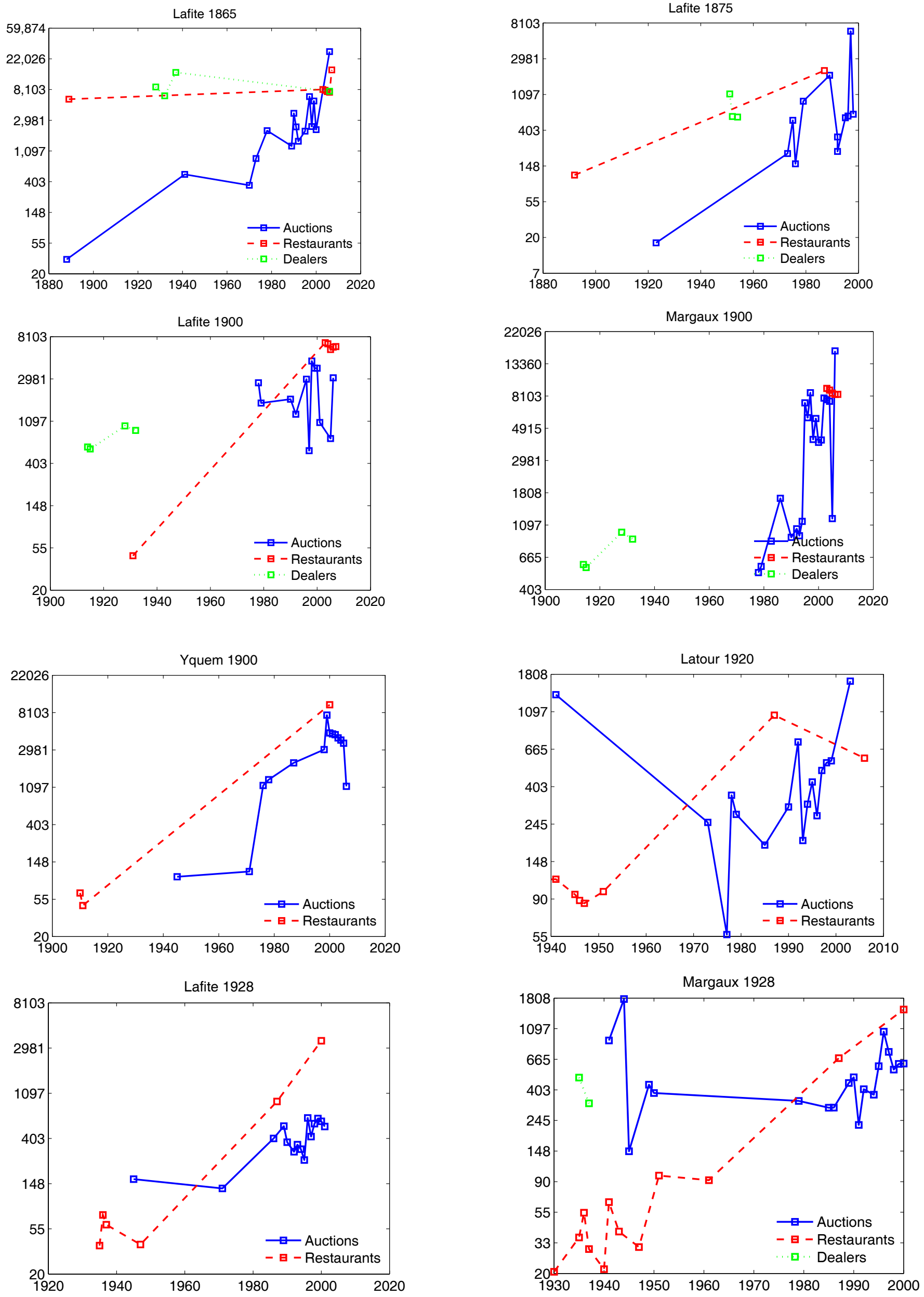

FIGURE A1: Historical prices of eight Bordeaux wines 


\section{Appendix 2: Many capital goods}

The point of this section is to show that Hotelling's analysis and our extension of it, hold when there are many goods. This is relevant to the application to wines.

Again in a partial-equilibrium, continuous-time context, we now extend the argument to the case in which there is more than one type of capital. This is important in our application, because with wine, each vintage is a different, but related nonrenewable commodity. ${ }^{23}$ Let $v$ denote the vintage of the capital, such as the vintage of the wine or of the artist in the case of, say, paintings. Sticking with continuous time, we may think of a continuum of vintages and may think of a vintage $v \in R$ as being any real number. Write the demand for this vintage as

$$
D^{v}(P)
$$

where $P$ is the infinite-dimensional price vector for all the other vintages, past, present and future. Once again, we assume an unbounded willingness to pay at small quantities, and so arbitrage across dates requires that under perfect foresight, the price of vintage $v$ should satisfy for all $t$

$$
p_{v, t}=p_{v} e^{r(t-v)}
$$

where $p_{v}$ is the initial price of the vintage- $v$ capital, so that we define $P: R^{2} \rightarrow$ $R_{+} \cup\{\infty\}$ by

$$
P=\left\{\begin{array}{ll}
p_{v} e^{r(t-v)} & \text { if } t \geq v \\
+\infty & \text { if } t<v
\end{array} .\right.
$$

Hotelling's equilibrium in many dimensions. - The initial stock of each vintage can be written as $k_{v}$. Instead of just one number, $p_{0}$, as we had above, we now have to solve for the vector $\left(p_{v}\right)_{v \in R}$ of the initial prices of each vintage. To solve for it, acting in the spirit of Hotelling we write the simultaneous equation system of resource-exhaustion conditions:

$$
k_{v}=\int_{0}^{\infty} D^{v}\left(P_{t}\right) d t, \quad v \in R
$$

which is to be solved for the vector $\left(p_{v}\right)_{v \in R}$.

Bubble equilibria in many dimensions. - As before, we replace (36) by the two conditions

$$
k_{v}=k_{v, C}+k_{v, \infty}
$$

and

$$
k_{v, C}=\int_{0}^{\infty} D^{v}\left(P_{t}\right) d t
$$

\footnotetext{
${ }^{23}$ Different vintages trade at vastly different prices. Some of the great vintages are 1865, 1870, 1900, 1929 and 1961. See Figure 1 of Jovanovic (2001) for estimated vintage effects.
} 
both holding for all $v \in R$. A no-bubble equilibrium is the one for which $k_{v, C}=k_{v}$ for all $v$. The rest are bubble equilibria on at least some of the vintages.

Example.-Consider the following static allocation problem of the consumer. His utility function depends on an array of capital goods $\left(x_{v}\right)_{v \leq t}$ and on an outside good $y$ in the following way:

$$
U\left[\left(x_{v}\right)_{v \leq t}, y\right]=y+X,
$$

where $X=\left(\int_{0}^{\infty} a_{v} x_{v}^{\rho} d v\right)^{1 / \rho}$ denotes the 'aggregate' capital good that, at date $t$, takes on the value

$$
X_{t}=\left(\int_{0}^{t} a_{v} x_{v}^{\rho} d v\right)^{1 / \rho}
$$

The consumer's date- $t$ income is $I_{t}$ and his budget constraint is

$$
I_{t}=y+\int_{0}^{t} p_{v, t} x_{v} d v
$$

The price of vintage- $v$ capital at date $t$ is given by (35). The Lagrangean is

$$
L=y+X_{t}-\lambda\left(I_{t}-y-\int_{-\infty}^{t} p_{v, t} x_{v} d v\right) .
$$

The first-order condition are $\lambda=1$ (for an interior optimum w.r.t. $y$ ), and $a_{v} x_{v}^{\rho-1} X_{t}^{1-\rho}=$ $p_{v, t}$, for each $v \in[0, t]$. Together with (35), the latter yield the demand functions

$$
x_{v, t}=\left(\frac{p_{v}}{a_{v}}\right)^{1 /(\rho-1)} X_{t} e^{r(t-v) /(\rho-1)} .
$$

Suppose that the time path of $X_{t}$ is determined. We now show that some vintages of capital can carry large bubbles while others need carry no bubbles. Suppose that vintage $t=0$ is priced according to its fundamental alone, i.e., that

$$
k_{0}=\left(\frac{p_{0}}{a_{0}}\right)^{1 /(\rho-1)} \int_{0}^{\infty} X_{t} e^{r t /(\rho-1)} d t
$$

whereas vintage $\varepsilon$ has a bubble, so that

$$
k_{\varepsilon}=k_{\varepsilon, \infty}+\left(\frac{p_{\varepsilon}}{a_{\varepsilon}}\right)^{1 /(\rho-1)} \int_{\varepsilon}^{\infty} X_{t} e^{r(t-\varepsilon) /(\rho-1)} d t
$$

Let $\varepsilon$ be small and suppose that the fundamentals of capital $\varepsilon$ and capital 0 are the same, i.e., that $a_{0}=a_{\varepsilon}$, and that $k_{0}=k_{\varepsilon}$. As $\varepsilon \rightarrow 0$, however,

$$
\frac{p_{\varepsilon}}{p_{0}} \rightarrow\left(1-\frac{k_{\infty}}{k_{0}}\right)^{\rho-1}
$$

which means that the prices can be quite different, depending on the magnitude of $k_{\infty}$ - the price ratio is unbounded. The difference between $p_{0}$ and $p_{\varepsilon}$ is due entirely to bubbles. 


\section{Appendix 3: Hotelling's equilibrium when there is depreciation}

Let us analyze first the example in Section 2.2.1. The example was $D(p)=p^{-\beta}$ with $\beta>1$. Then

$$
\begin{aligned}
\int_{0}^{t} e^{-\delta(t-s)} D\left(p_{0} e^{(r+\delta) s}\right) d s & =p_{0}^{-\beta} \int_{0}^{t} e^{-\delta(t-s)-\beta(r+\delta) s} d s \\
& =p_{0}^{-\beta} e^{-\delta t} \int_{0}^{t} e^{-[\beta r+(\beta-1) \delta] s} d s \\
& =p_{0}^{-\beta} e^{-\delta t} \frac{1-e^{-[\beta r+(\beta-1) \delta] t}}{\beta r+(\beta-1) \delta}
\end{aligned}
$$

Substituting into (9),

$$
k_{t}=e^{-\delta t}\left(k_{0}-p_{0}^{-\beta} \frac{1-e^{-[\beta(r+\delta)-\delta] t}}{\beta r+(\beta-1) \delta}\right),
$$

whence we see that the smallest $p_{0}$ that keeps the RHS of this equation non-negative for all $t$ is in (10). Substituting $p_{0}^{H}$ for $p_{0}$ into (40), we get (11).

\section{Appendix 4: The Planner's problem when there is a convenience yield}

Consider the planning problem. For the Planner, $c=-\frac{d k}{d t}$, and the Planner solves

$$
\max _{(k)_{0}^{\infty}} \int_{0}^{\infty} e^{-\rho t} U\left(-\dot{k}_{t}, k_{t}\right) d t
$$

subject to a given initial stock $k_{0}$. Formally, the Euler optimality condition is $e^{-\rho t} U_{k}=$ $-\frac{d}{d t} e^{-\rho t} U_{\dot{k}}$, which simplifies to

$$
U_{k}=\rho U_{\dot{k}}-U_{\dot{k} k} \dot{k}-U_{\dot{k} \dot{k}} \ddot{k}
$$

But if but if $k_{t}$ converges to a constant, $\dot{k}=\ddot{k}=0$ and (14) follows. 